\title{
Influences of moisture content and compressive loading speed on the mechanical properties of maize grain orientations
}

\author{
Farman Ali Chandio ${ }^{1,2}$, Yaoming $\mathrm{Li}^{1^{*}}$, Zheng Ma ${ }^{1}$, Fiaz Ahmad ${ }^{1,4}$, Tabinda Naz Syed ${ }^{3}$, \\ Sher Ali Shaikh ${ }^{1,2}$, Mazhar Hussain Tunio ${ }^{1,2}$ \\ (1. School of Agricultural Engineering, Jiangsu University, Zhenjiang 212000, Jiangsu, China; \\ 2. Faculty of Agricultural Engineering, Sindh Agriculture University, Tandojam 70060, Sindh, Pakistan; \\ 3. College of Engineering, Nanjing Agriculture University, Nanjing 210044, China; \\ 4. Department of Agricultural Engineering, Bahauddin Zakariya University, Multan 60800, Pakistan)
}

\begin{abstract}
Determination of the mechanical properties (rupture force, deformation, hardness, and toughness) of maize grain could be a significant concern for designing the harvester, thresher, and handling, processing, and storage equipment. Thus, the present research was conducted to assess the vertical and lateral rupture force, deformation, hardness, and toughness of maize grain (Beijing Denong, Lianchuang, Suyu 20, Liyu 88 and Suyu 29) influenced by different moisture contents (11.2\%, $17.5 \%$, and $21.3 \%$ ) and compressive loading speeds $(5,10,15,20$, and $25 \mathrm{~mm} / \mathrm{min}$, respectively). Besides, the mean length, width, thickness, geometric mean diameter, equivalent diameter, arithmetic diameter, sphericity, grain volume, surface area, and aspect ratio of the selected varieties were measured. The results showed that the highest length, width, thickness and sphericity, grain volume, surface area, and aspect ratio were obtained at moisture of $21.3 \%$, whereas the lowest was at $11.2 \%$. Moreover, it was observed that as increasing the loading speed from 5 to $25 \mathrm{~mm} / \mathrm{min}$, the vertical and lateral rupture forces decreased. However, as increasing moisture contents from $11.2 \%$ to $21.3 \%$, the vertical and lateral rupture forces, hardness, and toughness decreased noticeably. Furthermore, the maximum correlation $\left(R^{2}=0.9957\right)$ between rupture force and loading speed was found for Liyu 88 at moisture of $17.5 \%$ and minimum correlation $\left(R^{2}=0.7002\right)$ was found for Suyu 29 at moisture of 11.2\%. Moreover, the highest lateral and vertical rupture force was noticed $(p<0.05)$ at a loading speed of $5 \mathrm{~mm} / \mathrm{min}$. Based on the experimentally obtained results, it was concluded that the properties of maize grain evaluated were relevant to the design of planter, harvesters, thrashers, and processing machine.
\end{abstract}

Keywords: maize grain, moisture content, compressive loading speeds, mechanical properties, orientation DOI: $10.25165 /$ j.ijabe.20211404.6072

Citation: Chandio F A, Li Y M, Ma Z, Ahmad F, Syed T N, Shaikh S A, et al. Influences of moisture content and compressive loading speed on the mechanical properties of maize grain orientations. Int J Agric \& Biol Eng, 2021; 14(4): 41-49.

\section{Introduction}

Maize is an important economical cash crop and food material over the globe. Particularly in China, maize plays a pivotal role in the national economy. Data on the strength and physical properties of agricultural products are required for designing equipment and machine for efficient transporting, handling, processing, and storage, and are all focused on maize quality during harvesting, handling, transportation, separating, drying, aeration, sizing, storing, packing, and other processing. Accordingly, information about strength properties is needed not only for

Received date: 2020-08-08 Accepted date: 2020-11-08

Biographies: Farman Ali Chandio, PhD, Associate Professor, research interest: design of modern agricultural machinery, Email: farman_chandio@ hotmail.com; Zheng Ma, $\mathrm{PhD}$, Associate Researcher, research interest: design and research of modern agricultural machinery, Email: mazheng123@ujs.edu.cn; Fiaz Ahmad, PhD, Assistant Professor, research interest: mechanization engineering, Email: fiazahmad@bzu.edu.pk; Tabinda Naz Syed, PhD, research interest: design and research of modern agricultural machinery, Email:2020212024@stu.njau.edu.cn; Sher Ali Shaikh, PhD, research interest: design and research of modern agricultural machinery, Email: sashaikh@sau.edu.pk; Mazhar Hussain Tunio, $\mathrm{PhD}$, research interest: soil and water conservation, aeroponics, Email: mazharhussaintunio@sau.edu.pk.

*Corresponding authors: Yaoming Li, PhD, Professor, research interest: design and research of modern agricultural machinery. Email: ymli@ujs.edu.cn. agro-machine manufacturers but also for food scientists. Moreover, as a function of loading speed and moisture, physical and strength properties play an important role and help to design the processing, harvesting, separating, sizing and grinding, planting and storage equipment of maize grains. Regarding the mechanical properties of grains, compressive strength, modulus of elasticity, dent force, and other parameters were also considered. Hence, engineering data is required to study grain strength force to rupture under harvesting, handling, and drying conditions ${ }^{[1]}$.

The studies by Saul et al. ${ }^{[2]}$ and Shelef et al. ${ }^{[3]}$ reported that field shield maize could not be stored for more than a few hours without deterioration under high moisture content, even faster-drying rates required for damaged maize to prevent spoilage between harvesting and drying. Reference [4] reported that mechanically damaged maize has a lower market value and a lower export appeal. In the same direction, Gomez et al. ${ }^{[5]}$ confirmed that besides the risk of toxin formation, damaged kernels' detrimental effects are on miller's products. They added that mechanical damage also decreased seed maize viability and resulted in lower yields. Researchers have conducted many investigations to solve problems by studying products' mechanical properties. The rupture force of maize grains obtained a negative correlation with the peak viscosity of flour. At the same time, it was positively correlated with the amylase content of $\operatorname{starch}^{[6]}$. 
Few research studies have been conducted to explore the strength properties of grains such as apple ${ }^{[7]}$, desert date nuts ${ }^{[8]}$, pistachio nuts and kernel ${ }^{[9]}$, apricot pit and apricot seed ${ }^{[10,11]}$, sea buckthorn berries $^{[12]}$, potato ${ }^{[13]}$, caper fruit ${ }^{[14]}$, rice ${ }^{[15]}$ and wheat seeds ${ }^{[16]}$.

Researchers have investigated the mechanical properties of cereal products. The grain quality is seriously affected by the load from the threshing cylinder during the threshing and grinding processes. The challenge to decrease the grain damage is directly related to the threshing cylinder speed. Most agricultural materials are elastic in the first portion of a load-deformation curve but have viscoelastic properties with increased loading. Thus, the properties are time-dependent and the effect of loading rate becomes more noticeable ${ }^{[17]}$ as time extends. Singh et al. ${ }^{[18]}$ determined the force required to initiate rapture for cumin seed. The loading speed is directly proportional to the cylinder speed which is ultimately a decisive factor to ensure the grain quality and health at the post-harvesting stage. The behavior of maize grains with non-homogeneous organic structures under loading speed suggests a baseline for how to change grain behavior. Although previous work investigated mechanical properties of single grain by moisture contents, no information is available on changes in mechanical and viscoelastic properties of single maize grain during rupturing by loading from vertical and lateral orientation. This study hypothesized that a better understanding of the physical and strength properties of maize grains (five hybrid varieties cultivated in China) can help to decrease the grain damage during harvesting, threshing, and the processing phases at different moisture levels.

Therefore, the present study was planned to provide significant information by describing the physical and mechanical properties of maize grains of five varieties under different loading orientations and moisture contents.

\section{Materials and methods}

\subsection{Experiment setup}

The present research was carried out at the School of Agricultural Equipment Engineering, Jiangsu University, Zhenjiang, Jiangsu, China during 2018-2019. In this study, five maize grain varieties (Lianchuang, Beijing Denong, Suyu 20, Liyu 88 , and Suyu 29) were selected. The samples were collected from Wei Xing Agricultural Farm, Dantu District, Shiyezhen Town (32 $12^{\prime} 46.6^{\prime \prime} \mathrm{N}, 119^{\circ} 18^{\prime} 45.1$ "E) Zhenjiang, Jiangsu, China at the harvesting time. The collected grain samples were put into polyethylene bags and wrapped tightly for further processing.

\subsection{Maize grain sample preparation}

The collected samples were sieved through a coarse sieve $(12.7 \mathrm{~mm})$ and a 20 -mesh sieve $(0.85 \mathrm{~mm})$ on a medium-size Wiley Mill (Model X876249, Brook Crompton Parkinson Limited, Toronto, Ontario). Further, the coarse ground samples were then ground through a 40 -mesh sieve $(0.425 \mathrm{~mm})$ on the Wiley Mill to narrow the range of particle size to obtain the homogeneous samples. Maize grain samples were initially prepared from the harvesting to storage at moisture ranging from $9.3 \%$ to $41.5 \%{ }^{[15]}$. The moisture content of grains was examined at $11.2 \%, 17.5 \%$, and $21.3 \%( \pm 0.2 \%)$. The initial moisture content of maize grain samples was measured by a dry oven method and was kept constant throughout the experiment. The wrapped samples of grain were preserved and placed in the refrigerator to allow the water to be absorbed by samples for the uniform distribution of moisture for $48 \mathrm{~h}$. However, to maintain the moisture level of the grain, distilled water was added to samples accordingly as reported by Wang et al. ${ }^{[19]}$ and $\mathrm{Li}$ et al. ${ }^{[15]}$. Equation (1) was used for additional water calculation in maize grain.

$$
Q=\frac{W_{i}\left(M_{a}-M_{b}\right)}{100-M_{a}}
$$

where, $Q$ is the mass of water added, g; $W_{i}$ is the total seeds mass, g; $M_{a}$ is the initial moisture content, $\% ; M_{b}$ is the final moisture content, $\%$.

\subsection{Dimensional properties of maize grain}

The basic dimensions (width, thickness, length, sphericity, and surface area (see Figure 1)) were measured before each test at three moisture content levels $(11.2 \%, 17.5 \%$, and $21.3 \%)$. Also, the length, width, and thickness of maize grains were measured by a digital Vernier caliper. The geometric mean diameter $\left(D_{g}\right)$, equivalent diameter $\left(D_{e}\right)$, and arithmetic diameter $\left(D_{a}\right)$ were calculated using the given Equations (2)-(9) ${ }^{[20,21]}$.

$$
\begin{gathered}
D_{g}=(L W T)^{\frac{1}{3}} \\
D_{e}=\left\{L \frac{(W+T)^{2}}{4}\right\}^{\frac{1}{3}} \\
D_{a}=\frac{(L+W+T)}{3}
\end{gathered}
$$

where, $D_{g}$ is the geometric mean diameter, $\mathrm{mm} ; D_{e}$ is the equivalent diameter, $\mathrm{mm} ; D_{a}$ is the arithmetic diameter, $\mathrm{mm} ; L$ is the length, $\mathrm{mm} ; W$ is the width, $\mathrm{mm} ; T$ is the thickness, $\mathrm{mm}$. The sphericity of the grains was measured by Equation (5) by Kara et al. ${ }^{[20,21]}$

$$
S_{a}=\frac{(L W T)^{\frac{1}{3}}}{L} \times 100 \%
$$

where, $S_{a}$ is the sphericity, $\%$.

Volume and surface area were calculated by Equations (6)$(8)^{[22]}$.

$$
\begin{gathered}
V=0.25\left\{\left(\frac{\pi}{6}\right) L(W+T)^{2}\right\} \\
S=\frac{\pi B L^{2}}{(2 L-B)} \\
B=\sqrt{W T}
\end{gathered}
$$

where, $V$ is the volume, $\mathrm{mm}^{3} ; S$ is the surface area, $\mathrm{mm}^{2} ; B$ is the diameter of the spherical part of a grain, $\mathrm{mm}$.

The aspect ratio was assessed as follows ${ }^{[23]}$.

$$
R_{a}=\frac{W}{L}
$$

where, $R_{a}$ is the aspect ratio.

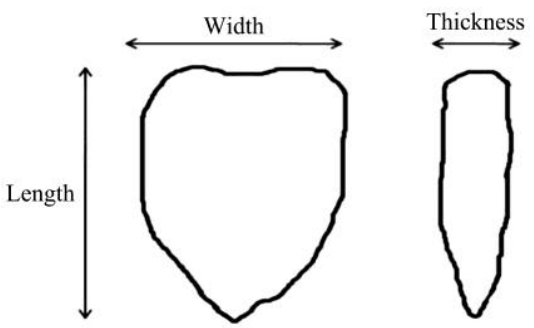

Figure 1 Schematic view of maize grain parameters

\subsection{Compression test}

The mechanical compression tests were performed using the texture analyzer machine (TA.XTplusC stable microsystems, AZoNetwork Ltd. Manchester, UK). The texture analyzer machine consisted of a load cell $(500 \mathrm{~N})$ connected to the upper plate for the detection of applied force, a lower plate mounted to a driving unit, and a personal computer equipped with a data acquisition system. 
The homogeneous maize samples were randomly selected for the test of rupture force, deformation, hardness, and toughness at rupture points under different moisture content levels (11.2\%, $17.5 \%$, and 21.3\%) for Beijing Denong, Lianchuang, Suyu 20, Liyu 88 and Suyu 29. The maize samples were placed at the center of the machine batch and five loading speeds (deformation rate) of 5 , $10,15,20$, and $25 \mathrm{~mm} / \mathrm{min}$, respectively, were applied. The rupture force tests were comprised of two orientations (vertical and lateral) of maize grains through the texture analyzer machine (Figure 2). The texture analyzer machine calculated the applied load on maize rupturing. Force-deformation curves of each maize grain of the five varieties were done for vertical and lateral orientations (Figure 2) at different moisture contents. Generally, the rupture force rate increased with the increase of deforming until reaching a maximum value. Then the data were transmitted to a data acquisition system (DAS) for obtaining force versus time curve. Each orientation procedure was replicated five times.

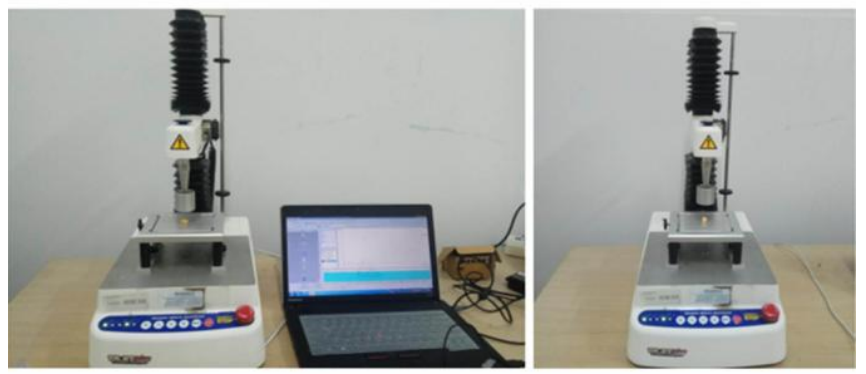

Figure 2 Vertical and lateral orientations of maize grains on the texture analyzer machine

\subsubsection{Toughness}

Rupture energy of maize grains was assessed by following mathematical equation from Tavakoli et al. ${ }^{[24]}$

$$
\mathrm{RE}=F \cdot D / 2
$$

where, $\mathrm{RE}$ is the rupture energy, $\mathrm{MJ} ; F$ is the rupture force, $\mathrm{N} ; D$ is the deformation at rupture point, $\mathrm{mm}$. Toughness was calculated by following a mathematical equation from Gupta et al. ${ }^{[25]}$.

$$
P=R E / V
$$

where, $P$ is toughness, $\mathrm{MJ} / \mathrm{mm}^{3} ; V$ is volume, $\mathrm{mm}^{3}$.

2.4.2 Hardness

The hardness of maize grains was calculated by the following mathematical expression ${ }^{[25,26]}$ :

$$
H=\frac{F}{D}
$$

where, $H$ is the hardness, $\mathrm{N} / \mathrm{mm}$.

\subsection{Statistical analysis}

The experiment was conducted with a factorial statistical design of 135 treatments (5 maize grain varieties, 3 moisture contents, and 5 loading speeds) including five replications. SPSS determines the significance of the treatments and error uncertainty. The test data were analyzed by analysis of variance (ANOVA), and Duncan's multiple comparisons were used to determine the difference at a $p<0.05$ level of significance.

\section{Results and discussion}

The results of ANOVA for moisture content, varieties, and loading speed effect on the vertical and lateral rupture force of maize grains are presented in Tables 1 and 2. It was found that the interaction effects of moisture content $\times$ loading speed, moisture content $\times$ varieties, loading speed $\times$ varieties, and moisture content $\times$ loading speed $\times$ variety on the vertical and lateral rupture force were significant $(p<0.001)$.
Table 1 ANOVA of lateral forces of maize varieties

\begin{tabular}{cccccc}
\hline Source & DF & SS & MS & $F$ & $p$ \\
\hline $\mathrm{R}$ & 2 & 1 & 0.42601 & & \\
Varieties & 4 & 907956 & 226989 & 59697.4 & 0.0000 \\
Moisture contents & 2 & 587601 & 293800 & 77268.6 & 0.0000 \\
Speed & 4 & 33065 & 8266.34 & 2174.02 & 0.0000 \\
$\mathrm{~V} \times \mathrm{M}$ & 8 & 42705 & 5338.10 & 1403.90 & 0.0000 \\
$\mathrm{~V} \times \mathrm{S}$ & 16 & 458 & 28.6214 & 7.53 & 0.0000 \\
$\mathrm{M} \times \mathrm{S}$ & 8 & 7579 & 4.6332 & 24.89 & 0.0000 \\
$\mathrm{~V} \times \mathrm{M} \times \mathrm{S}$ & 32 & 1965 & 61.4009 & 16.15 & 0.0000 \\
Error & 148 & 563 & 3.80233 & & \\
Total & 224 & 1575070 & & & \\
\hline Note: V represents varieties; S represents speed; M represents moisture contents.
\end{tabular}

Table 2 ANOVA of vertical forces of maize varieties

\begin{tabular}{cccccc}
\hline Source & DF & SS & MS & $F$ & $p$ \\
\hline $\mathrm{R}$ & 2 & 6 & 3 & & \\
Varieties & 4 & 761313 & 190328 & 51174.8 & 0.0000 \\
Moisture contents & 2 & 164644 & 82322 & 22134.4 & 0.0000 \\
Speed & 4 & 40544 & 10136 & 2725.33 & 0.0000 \\
$\mathrm{~V} \times \mathrm{M}$ & 8 & 47266 & 5908 & 1588.59 & 0.0000 \\
$\mathrm{~V} \times \mathrm{S}$ & 16 & 963 & 60 & 16.19 & 0.0000 \\
$\mathrm{M} \times \mathrm{S}$ & 8 & 2317 & 290 & 77.89 & 0.0000 \\
$\mathrm{~V} \times \mathrm{M} \times \mathrm{S}$ & 32 & 1668 & 52 & 14.02 & 0.0000 \\
Error & 148 & 550 & 4 & & \\
Total & 224 & 1019273 & & & \\
\hline
\end{tabular}

Note: V represents varieties; $\mathrm{S}$ represents speed; $\mathrm{M}$ represents moisture contents.

\subsection{Dimensional (size and shape) properties of maize grain varieties}

The dimension properties of maize grain under different moisture contents $(11.2 \%, 17.5 \%$, and $21.3 \%)$ are represented in Table 3. As can be seen that the average length of Beijing Denong, Lianchuang, Suyu 20, Liyu 88, and Suyu 29 were ranged from 12.70 to $13.32 \mathrm{~mm}, 11.80$ to $12.30 \mathrm{~mm}, 11.20$ to $11.84 \mathrm{~mm}$, 10.90 to $11.42 \mathrm{~mm}$, and 10.40 to $10.86 \mathrm{~mm}$ at the moisture content of $11.2 \%$ to $21.3 \%$, respectively. However, the average width of maize grain was ranged from 8.10 to $8.45 \mathrm{~mm}, 7.30$ to $7.82 \mathrm{~mm}$, 7.12 to $7.81 \mathrm{~mm}, 6.90$ to $7.21 \mathrm{~mm}$, and 6.45 to $6.71 \mathrm{~mm}$ for Beijing Denong, Lianchuang, Suyu 20, Liyu 88 and Suyu 29, respectively. The average thickness of maize grains was ranged from 4.90 to $5.31 \mathrm{~mm}, 4.70$ to $5.01 \mathrm{~mm}, 4.65$ to $4.86 \mathrm{~mm}, 4.61$ to 4.79 , and 4.59 to $4.74 \mathrm{~mm}$ for Beijing Denong, Lianchuang, Suyu 20, Liyu 88, and Suyu 29, respectively. Furthermore, the results of length, width, and thickness indicated that increasing the moisture content of the grain significantly increased the geometric dimensions. Similarly, the highest length, width, and thickness were found at moisture of $21.3 \%$, and the lowest one was found at $11.2 \%$ moisture content. Milani et al. ${ }^{[27]}$ also reported similar results for cucurbit seeds.

The geometric mean diameter of maize grain was ranged from 7.95 to $8.39 \mathrm{~mm}$ for Beijing Denong, 7.36 to $7.80 \mathrm{~mm}$ for Lianchuang, 7.17 to $7.64 \mathrm{~mm}$ for Suyu 20, 6.98 to $7.28 \mathrm{~mm}$ for $\mathrm{Li}$ $\mathrm{Fu} 88$, and 6.68 to $6.94 \mathrm{~mm}$ for $\mathrm{Su} \mathrm{Fu} 29$ as moisture content varies from $11.2 \%$ to $21.3 \%$. Moreover, the equivalent diameter of maize grain varied from 7.79 to $8.24 \mathrm{~mm}$ for Beijing Denong, 7.25 to $7.68 \mathrm{~mm}$ for Lianchuang, 7.06 to $7.50 \mathrm{~mm}$ for Suyu 20, 6.88 to $7.18 \mathrm{~mm}$ for $\mathrm{Li} \mathrm{Fu} \mathrm{88,} \mathrm{and} 6.62$ to $6.88 \mathrm{~mm}$ for $\mathrm{Su} \mathrm{Fu} 29$ when moisture content varying from $11.2 \%$ to $21.3 \%$. Further, the arithmetic diameter of maize grain varieties was varied from 8.56 to $9.02 \mathrm{~mm}$ for Beijing Denong, 7.93 to $8.37 \mathrm{~mm}$ for Lianchuang, 
7.69 to $8.17 \mathrm{~mm}$ for Suyu 20, 7.47 to $7.80 \mathrm{~mm}$ for $\mathrm{Li} \mathrm{Fu} \mathrm{88,} \mathrm{and}$ 7.14 to $7.43 \mathrm{~mm}$ for Su Fu 29 when moisture content varying from $11.2 \%$ to $21.3 \%$. This is similar to the results of the study of sweet maize physical properties by Karababa and Coşkuner ${ }^{[28]}$ and the measured data for dent maize kernels presented by Esref and Nazmi ${ }^{[29]}$.

Table 3 Dimensional properties of maize grain at moisture contents of $11.20 \%, 17.50 \%$ and $21.30 \%$

\begin{tabular}{|c|c|c|c|c|c|c|c|}
\hline Maize grain varieties & $\mathrm{MC} / \%$ & $L / \mathrm{mm}$ & $W / \mathrm{mm}$ & $T / \mathrm{mm}$ & $D_{g} / \mathrm{mm}$ & $D_{e} / \mathrm{mm}$ & $D_{a} / \mathrm{mm}$ \\
\hline Beijing Denong & $11.20 \%$ & $12.7 \pm 1.05$ & $8.1 \pm 0.95$ & $4.9 \pm 1.13$ & $7.95 \pm 0.20$ & $7.79 \pm 0.26$ & $8.56 \pm 1.04$ \\
\hline Beijing Denong & $17.50 \%$ & $13.21 \pm 1.21$ & $8.31 \pm 0.99$ & $5.19 \pm 1.24$ & $8.26 \pm 0.22$ & $8.11 \pm 0.28$ & $8.90 \pm 1.14$ \\
\hline Beijing Denong & $21.30 \%$ & $13.32 \pm 1.20$ & $8.45 \pm 1.15$ & $5.31 \pm 0.93$ & $8.39 \pm 0.23$ & $8.24 \pm 0.27$ & $9.02 \pm 1.09$ \\
\hline Lianchuang & $11.20 \%$ & $11.8 \pm 0.99$ & $7.3 \pm 1.19$ & $4.7 \pm 0.95$ & $7.36 \pm 0.17$ & $7.25 \pm 0.25$ & $7.93 \pm 1.04$ \\
\hline Lianchuang & $17.50 \%$ & $12.19 \pm 1.02$ & $7.73 \pm 0.94$ & $4.92 \pm 1.12$ & $7.71 \pm 0.19$ & $7.58 \pm 0.26$ & $8.28 \pm 1.02$ \\
\hline Suyu 20 & $11.20 \%$ & $11.20 \pm 1.3$ & $7.12 \pm 1.09$ & $4.65 \pm 1.02$ & $7.17 \pm 0.16$ & $7.06 \pm 0.25$ & $7.69 \pm 4.47$ \\
\hline Suyu 20 & $17.50 \%$ & $11.72 \pm 1.01$ & $7.38 \pm 1.07$ & $4.78 \pm 1.13$ & $7.41 \pm 0.18$ & $7.30 \pm 0.25$ & $7.96 \pm 1.07$ \\
\hline Suyu 20 & $21.30 \%$ & $11.84 \pm 0.98$ & $7.81 \pm 1.13$ & $4.86 \pm 1.13$ & $7.64 \pm 0.19$ & $7.50 \pm 0.26$ & $8.17 \pm 1.08$ \\
\hline Liyu 88 & $11.20 \%$ & $10.90 \pm 1.01$ & $6.90 \pm 1.12$ & $4.61 \pm 0.87$ & $6.98 \pm 0.16$ & $6.88 \pm 0.24$ & $7.47 \pm 1.00$ \\
\hline Liyu 88 & $17.50 \%$ & $11.30 \pm 0.99$ & $7.09 \pm 0.87$ & $4.71 \pm 1.01$ & $7.18 \pm 0.17$ & $7.08 \pm 0.24$ & $7.70 \pm 0.95$ \\
\hline Liyu 88 & $21.30 \%$ & $11.42 \pm 1.07$ & $7.21 \pm 1.24$ & $4.79 \pm 084$ & $7.28 \pm 0.17$ & $7.18 \pm 0.25$ & $7.80 \pm 1.05$ \\
\hline Suyu 29 & $17.50 \%$ & $10.73 \pm 0.98$ & $6.62 \pm 1.03$ & $4.65 \pm 0.97$ & $6.84 \pm 0.15$ & $6.78 \pm 0.23$ & $7.33 \pm 0.99$ \\
\hline Suyu 29 & $21.30 \%$ & $10.86 \pm 1.11$ & $6.71 \pm 0.95$ & $4.74 \pm 0.85$ & $6.94 \pm 0.15$ & $6.88 \pm 0.23$ & $7.43 \pm 0.97$ \\
\hline
\end{tabular}

\subsection{Moisture effects on dimensional properties}

\subsubsection{Sphericity}

The results of the sphericity of the maize grain at different moisture contents are presented in Figure 3a. The sphericity varied from, $61.37 \% \pm 0.07 \%$ to $61.90 \% \pm 0.08 \%$ for Lianchuang, $61.45 \% \pm 0.07 \%$ to $62.44 \% \pm 0.07 \%$ for Beijing Denong, $62.51 \% \pm 0.09 \%$ to $63.38 \% \pm 0.07 \%$ for Suyu $20,62.69 \% \pm 0.09 \%$ to $63.20 \% \pm 0.07 \%$ for Liyu 88 and $63.18 \% \pm 0.09 \%$ to $63.70 \% \pm 0.09 \%$ for Suyu 29. Furthermore, Suyu 29 had the highest sphericity $(63.70 \% \pm 0.08 \%)$ under moisture of $11.2 \%$ and Liang Chuang has the lowest sphericity under moisture of $11.2 \%$. The results of the
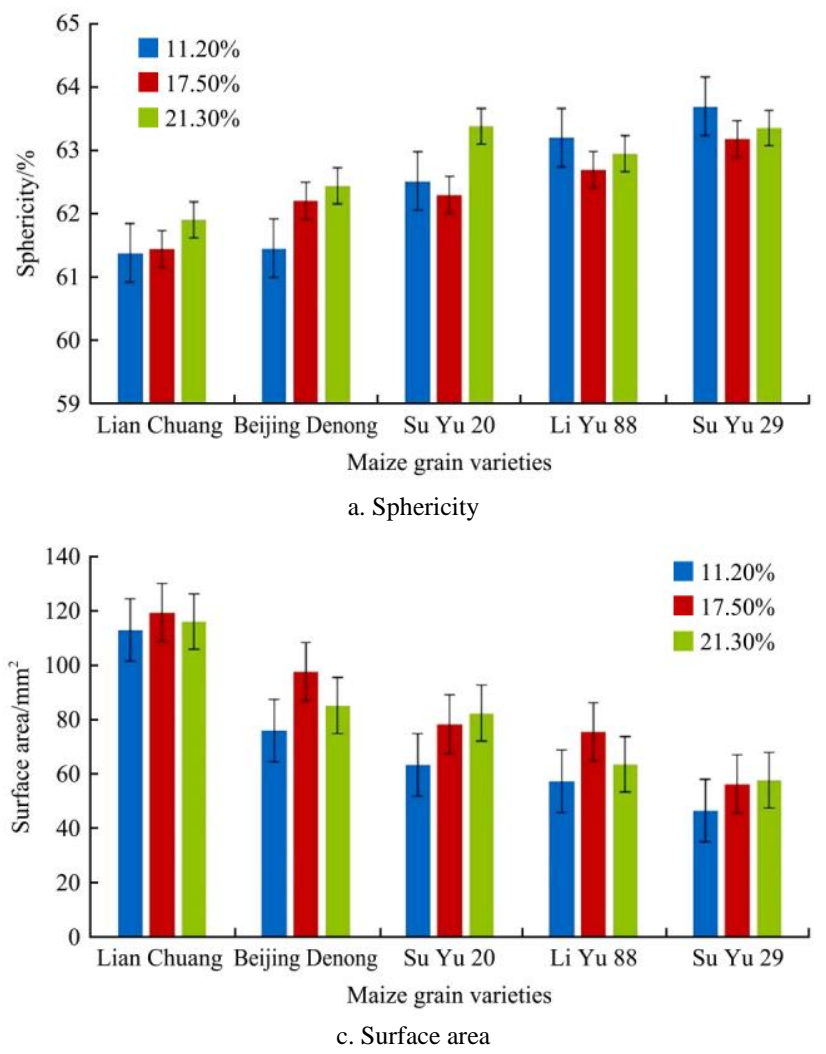

Lianchuang variety are in agreement with the results of Karababa et al. $^{[28]}$ for sweet maize.

\subsubsection{Volume}

The results of the volume of maize grain at different moisture contents are represented in Figure 3b. It was found that volume increased with the increase of moisture content. The volume varied from $(280.80 \pm 14.79)$ to $(329.95 \pm 16.94) \mathrm{mm}^{3}$ for Lianchuang, $(222.31 \pm 12.81)$ to $(264.89 \pm 13.85) \mathrm{mm}^{3}$ for Beijing Denong, $(204.80 \pm 12.69)$ to $(248.67 \pm 14.29) \mathrm{mm}^{3}$ for Suyu 20, $(188.92 \pm 10.83)$ to $(215.15 \pm 12.39) \mathrm{mm}^{3}$ for Liyu 88 and $(165.84 \pm 9.47)$ to $(186.27 \pm 10.15) \mathrm{mm}^{3}$ for Suyu 29 , respectively.
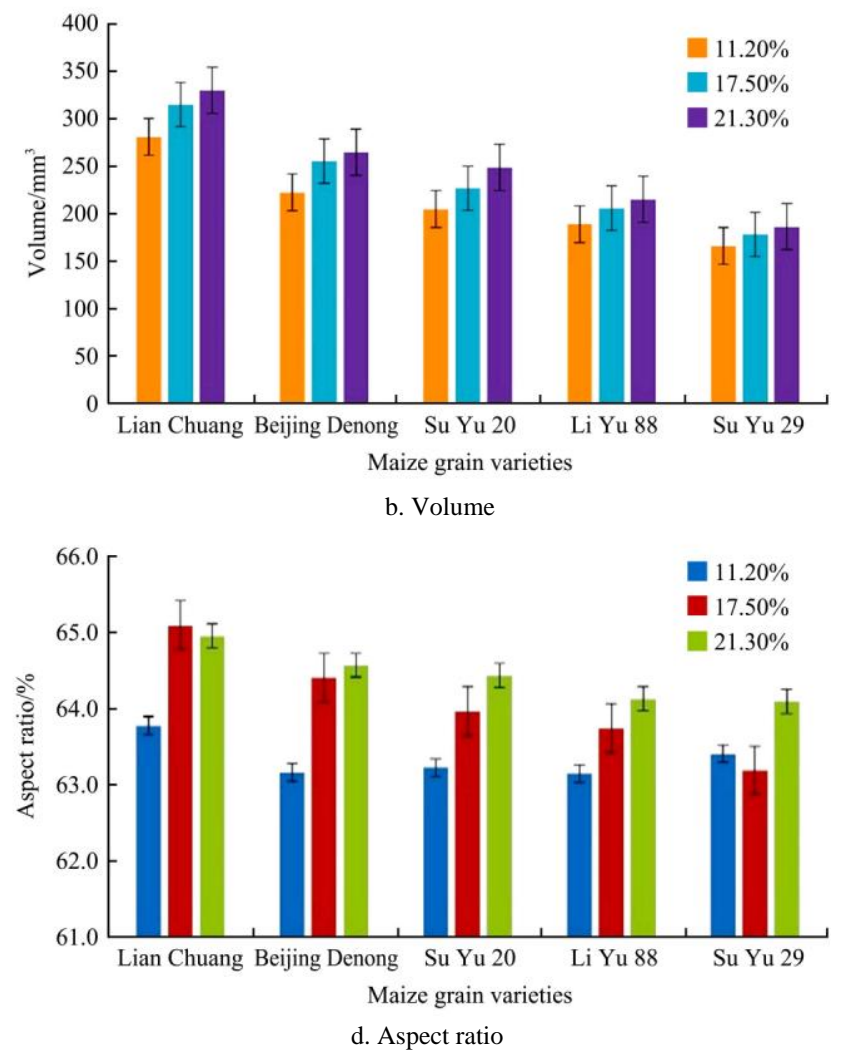

Figure 3 Effects of moisture content on the dimensional properties of maize grain 
Furthermore, the lowest volume was observed for Suyu 29 $\left((165.84 \pm 9.47) \mathrm{mm}^{3}\right)$, whereas the highest was obtained for Lianchuang $\left((329.95 \pm 16.94) \mathrm{mm}^{3}\right)$. These observations agree with that from Deshpande et al. ${ }^{[30]}$ for gram, Altuntas and Yildiz ${ }^{[31]}$ for faba bean and Javed et al. ${ }^{[32]}$

\subsubsection{Surface area}

The surface areas of maize grain at different moisture contents are presented in Figure 3c. Surface areas varied from (113.01 \pm $7.39)$ to $(119.37 \pm 1.05) \mathrm{mm}^{2}$ for Liang Chuang, $(76.00 \pm 1.08) \mathrm{mm}^{2}$ to $(97.58 \pm 1.84) \mathrm{mm}^{2}$ for Beijing Denong, $(63.39 \pm 1.70) \mathrm{mm}^{2}$ to $(82.34 \pm 1.12) \mathrm{mm}^{2}$ for Suyu $20,(57.34 \pm 1.66) \mathrm{mm}^{2}$ to $(75.49 \pm 1.25)$ for Liyu 88 and $(46.56 \pm 1.62) \mathrm{mm}^{2}$ to $(57.66 \pm 1.89) \mathrm{mm}^{2}$ Suyu 29 , respectively.

Further, results proved that with increasing the moisture level from $11.2 \%$ to $21.3 \%$, the highest surface area was found for Lianchuang (119.37 \pm 1.05$)$. There was no significant difference between different moisture contents for the same variety.

\subsubsection{Aspect ratio}

The aspect ratio of maize grain at different moisture contents is presented in Figure 3d. The aspect ratio increased with the increase of moisture content except for Suyu 29. The aspect ratio varied from $63.78 \% \pm 0.15 \%$ to $65.01 \% \pm 0.15 \%$ for Lianchuang, $63.16 \% \pm 0.12 \%$ to $64.96 \% \pm 0.14 \%$ for Beijing Denong, $63.22 \% \pm$

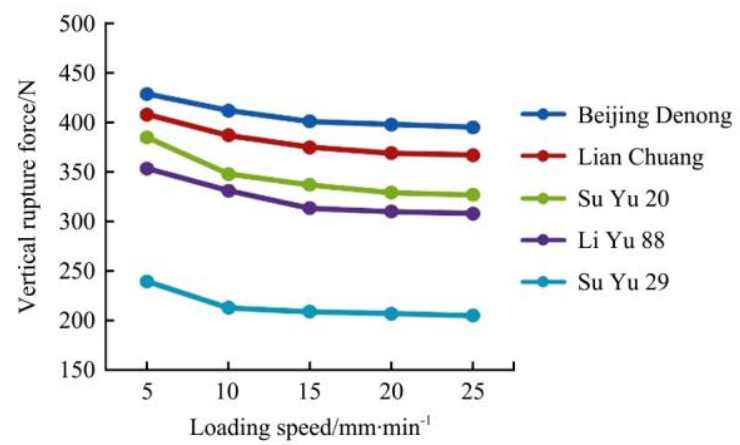

a. Vertical rupture force of maize grain varieties at moisture of $11.2 \%$

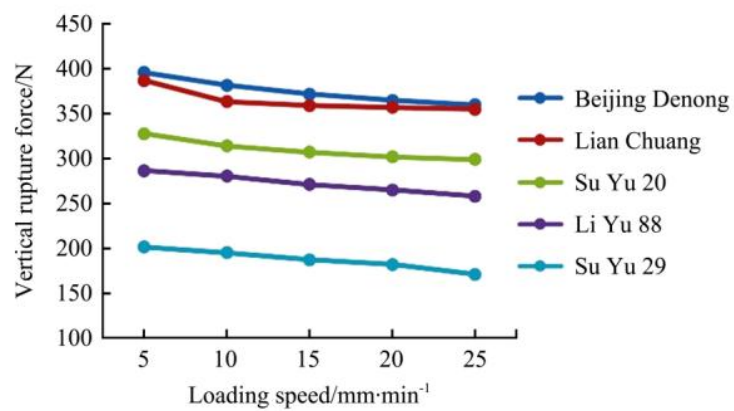

c. Vertical rupture force of maize grain at moisture of $17.5 \%$

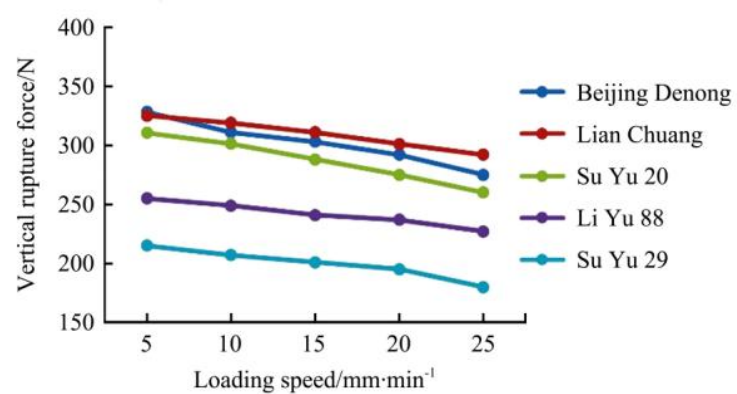

e. Vertical rupture force of maize grain at moisture of $21.3 \%$
$0.15 \%$ to $64.43 \% \pm 0.15 \%$ for Suyu $20,63.13 \% \pm 0.16 \%$ to $64.13 \% \pm$ $0.16 \%$ for Liyu 88 , and $63.41 \% \pm 0.17 \%$ to $64.09 \% \pm 0.15 \%$ for Suyu 29, respectively. Figure $3 \mathrm{~d}$ shows that aspect ratio increases as moisture content increase except for Suyu 29 and Lianchuang, the implies that swelling as a result of the increase in moisture was pronounced in aspect ratio, which might be attributable to the absorb moisture rate of grains accelerated with increased moisture contents. Similar effects of moisture contents on the aspect ratio of soybean were reported by Ilknur et al. ${ }^{[33]}$

\subsection{Loading speed effect on vertical and lateral rupture force}

3.3.1 Vertical and lateral rupture force at moisture of $11.2 \%$

Vertical and lateral rupture force of maize grain under different loading speeds $(5,10,15,20$, and $25 \mathrm{~mm} / \mathrm{min})$ at moisture of $11.2 \%$ are presented in Figures $4 \mathrm{a}$ and $4 \mathrm{~b}$. The vertical rupture force of maize grain ranged from $428.81 \mathrm{~N}$ to $395.00 \mathrm{~N}$ for Beijing Denong, $408.09 \mathrm{~N}$ to $367.00 \mathrm{~N}$ for Lianchuang, $385.08 \mathrm{~N}$ to $327.00 \mathrm{~N}$ for Suyu 20, 353.47 to $308 \mathrm{~N}$ for Liyu 88, and 239.43 to $205.00 \mathrm{~N}$ for Suyu 29 at loading speed of $5-25 \mathrm{~mm} / \mathrm{min}$ and moisture of $11.2 \%$. Furthermore, the lateral force of maize grain ranged from 842.31 to $796.00 \mathrm{~N}$ for Beijing Denong, 830.28 to $790.00 \mathrm{~N}$ for Lianchuang, 713 to $683 \mathrm{~N}$ for Suyu 20, 702.74 to $670.00 \mathrm{~N}$ for Liyu 88, and 799.49 to $758.00 \mathrm{~N}$ for Suyu 29 at loading speed of $5-25 \mathrm{~mm} / \mathrm{min}$ and moisture of $11.2 \%$.

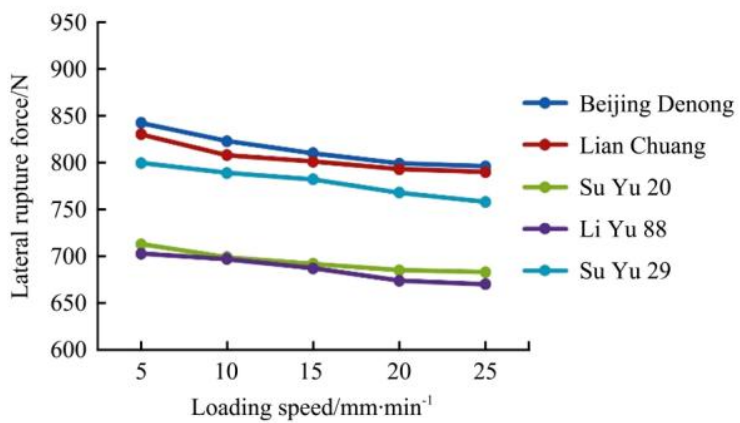

b. Lateral rupture force of maize grain varieties at moisture of $11.2 \%$

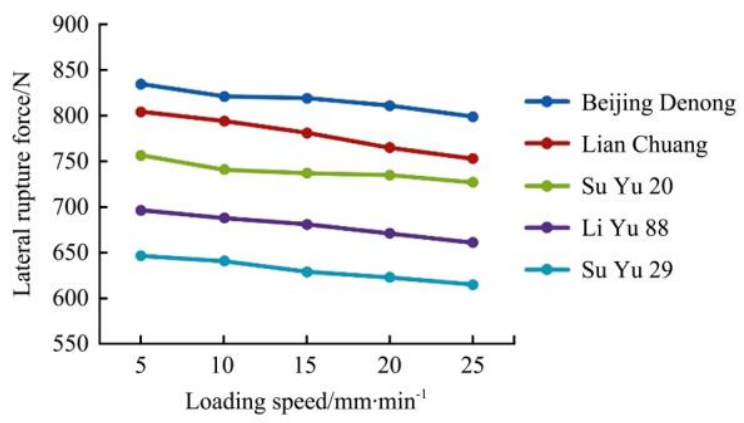

d. Lateral rupture force of maze grain at moisture of $17.5 \%$

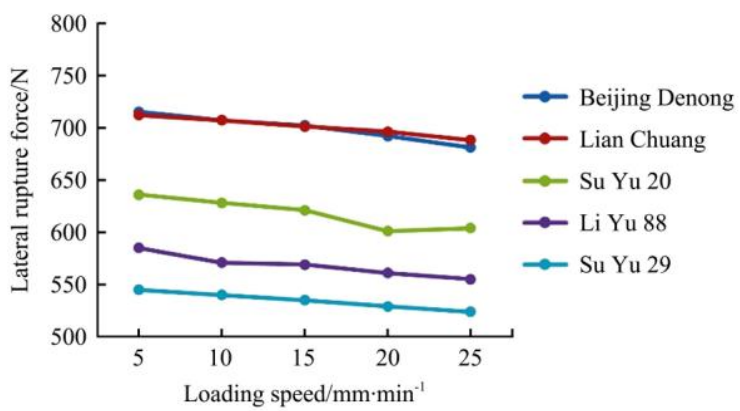

f. Lateral rupture force of maize grain at moisture of $21.3 \%$

Figure 4 Variation of vertical and lateral rupture force over loading speed of maize grain at different moistures

Maximum correlation $\left(R^{2}=0.9916\right)$ between lateral rupture forces and loading speed was obtained for Suyu 29, whereas minimum correlation $\left(R^{2}=0.9263\right)$ was obtained for Suyu 20 at moisture of $11.2 \%$. Similarly, the highest correlation $\left(R^{2}=0.8763\right)$ 
between vertical rupture forces and loading speed was found for Lianchuang, while the lowest $\left(R^{2}=0.7002\right)$ was found for Suyu 29 at moisture of $11.2 \%$. The sensitivity of maize grains to breakage depended on grain moisture content from $15 \%$ to $30 \%{ }^{[34]}$. Moreover, vertical rupture force decreased with the increase of loading speeds.

\subsubsection{Vertical and lateral rupture force at moisture of $17.5 \%$}

Vertical and lateral rupture force of maize grain under different loading speeds $(5,10,15,20$, and $25 \mathrm{~mm} / \mathrm{min})$ at moisture of $17.5 \%$ are presented in Figures $4 \mathrm{c}$ and $4 \mathrm{~d}$. The vertical rupture force of maize grain ranged from 395.97 to $360.00 \mathrm{~N}$ for Beijing Denong, 386.94 to $355.00 \mathrm{~N}$ for Lianchuang, 327.67 to $299.00 \mathrm{~N}$ for Suyu 20, 286.5 to $258.0 \mathrm{~N}$ for Liyu 88, and 201.34 to $171.00 \mathrm{~N}$ for Suyu 29 at loading speed of 5$25 \mathrm{~mm} / \mathrm{min}$ and moisture of $17.5 \%$. Further, the lateral force of maize grain ranged from 834.5 to $799.0 \mathrm{~N}$ for Beijing Denong, 804.3 to $753.0 \mathrm{~N}$ for Lianchuang, 756.65 to $727.00 \mathrm{~N}$ for Suyu 20, 696.46 to $661.00 \mathrm{~N}$ for Liyu 88, and 646.61 to $615.00 \mathrm{~N}$ for Suyu 29 respectively, at loading speed of $5-25 \mathrm{~mm} / \mathrm{min}$ and moisture of $17.5 \%$.

Maximum correlation $\left(R^{2}=0.9953\right)$ between lateral rupture forces and loading speed was obtained for Lianchuang, whereas minimum correlation $\left(R^{2}=0.8902\right)$ was obtained for Suyu 20 at moisture of $17.5 \%$. Similarly, the highest correlation $\left(R^{2}=0.9957\right)$ between vertical rupture forces and loading speed was found for Liyu 88 while the lowest $\left(R^{2}=0.9207\right)$ was found for Suyu 20 at moisture of $17.5 \%$.

3.3.3 Vertical and lateral rupture force at moisture of $21.3 \%$

Results of vertical and lateral rupture force of maize grain over loading speeds at moisture of $21.3 \%$ are displayed in Figures 4e and $4 \mathrm{f}$. The vertical rupture force of maize grain ranged from 328.2 to $275.0 \mathrm{~N}, 325$ to $292 \mathrm{~N}, 310.5$ to $260.0 \mathrm{~N}, 255$ to $227 \mathrm{~N}$, and 215 to $180 \mathrm{~N}$ under the loading speed of $5-25 \mathrm{~mm} / \mathrm{min}$, respectively for Beijing Denong, Lianchuang, Suyu 20, Liyu 88 and Suyu 29 at moisture of $21.3 \%$. Further, the lateral force of maize grain varieties ranged from 715 to $688 \mathrm{~N}, 712$ to $688 \mathrm{~N}, 636$ to $604 \mathrm{~N}, 585$ to $555 \mathrm{~N}, 545$ to $524 \mathrm{~N}$ for Beijing Denong, Lianchuang, Suyu 20, Liyu 88, and Suyu 29, respectively, at moisture of $21.3 \%$ and loading speed of $5-25 \mathrm{~mm} / \mathrm{min}$.

Maximum correlation $\left(R^{2}=0.9937\right)$ between vertical rupture forces and loading speed was obtained for Suyu 20, whereas minimum correlation $\left(R^{2}=0.9617\right)$ was obtained for Suyu 29 at moisture of $21.3 \%$. Similarly, the highest correlation $\left(R^{2}=0.9923\right)$ of lateral rupture forces was found for Lianchuang, while the lowest $\left(R^{2}=0.9021\right)$ was found for Suyu 20 at moisture of $21.3 \%$.

From Figures 7-12, the results revealed that the highest vertical and lateral rupture forces were obtained at moisture of $11.2 \%$ for the same variety, whereas the lowest achieved at moisture of $21.3 \%$. This was because when the maize grains were compressed, further absorption of water by shell made the grain interior swell up and fill the clearance between the grain and shell.

Furthermore, while increasing the moisture content from $11.2 \%$ to $21.3 \%$, lateral rupture forces decreased for Suyu 29. Similar results were stated that the rupture force (dimension behavior) decreased with increase in moisture levels of maize grain $^{[35]}$. Babic et al. ${ }^{[36]}$ demonstrated that compressive strength properties decreased as the moisture content of maize seeds increased. A significant decrease in the linear limit of load was observed with an increase of moisture of maize grain. Duncan's test showed noticeable $(p<0.05)$ differences among the moisture contents and maize grain varieties.

\subsection{Interaction effects on vertical and lateral rupture force}

3.4.1 Interaction effect of varieties and loading speed

Interaction effect of varieties and loading speed on vertical and lateral rupture force are presented in Figure 5a. It indicated that vertical and lateral rupture force varied from (380.64 to $342.33 \mathrm{~N}$, 377.39 to $295.33 \mathrm{~N}, 341.04$ to $295.33 \mathrm{~N}, 297.98$ to 264.33 and 218.59 to $185.33 \mathrm{~N}$ ) and (732.22 to $693.67 \mathrm{~N}, 747.26$ to $708.67 \mathrm{~N}$, 651.87 to $621.33 \mathrm{~N}, 611.39$ to $578.67 \mathrm{~N}, 580.36$ to $549.00 \mathrm{~N}$ ) with the change of loading speed for Beijing Denong, Lianchuang, Suyu 20, Liyu 88 and Suyu 29, respectively. Further, the highest vertical and lateral rupture force was obtained by Beijing Denong and Liang Chuang, respectively, and the lowest was by Suyu 29.

Moreover, the vertical and lateral rupture forces were significantly different $(p<0.05)$ for Suyu 29 . Similarly, Duncan's multiple range test showed that vertical and lateral rupture forces are significantly different $(p<0.05)$ for all varieties.

\subsubsection{Interaction effect of varieties and moisture contents}

The interaction effect of maize grain varieties and moisture contents on vertical and lateral rupture force are presented in Figure $5 \mathrm{~b}$. The data indicated that vertical and lateral rupture force varied from (406.96 to $309.60 \mathrm{~N}, 381.81$ to $301.82 \mathrm{~N}, 345.22$ to $286.93 \mathrm{~N}, 322.96$ to $241.80 \mathrm{~N}$ and 214.69 to $199.60 \mathrm{~N})$ and $(754.46$ to $650.80 \mathrm{~N}, 764.06$ to $649.40 \mathrm{~N}, 644.4$ to $568.0 \mathrm{~N}, 636.14$ to $518.00 \mathrm{~N}$ and 629.5 to $484.6 \mathrm{~N}$ ) at the moisture of $11.2 \%, 17.5 \%$, and $21.3 \%$ for Beijing Denong, Lianchuang, Suyu 20, Liyu 88 and Suyu 29 respectively. Furthermore, the highest vertical and lateral rupture force (406.96 and 754.46 N) was observed for Beijing Denong at $11.2 \%$ and $17.5 \%$, respectively. Whereas, lowest $(199.6$ and $484.6 \mathrm{~N})$ were found at $17.5 \%$ and $21.3 \%$ for Suyu 29 , respectively.

Moreover, increasing the moisture content from $11.2 \%$ to $21.3 \%$, lateral rupture force had decreased for Suyu 29. The individual grains appeared more resistant to breakage under the lateral loading than under the vertical loading due to sphericity and aspect ratio. There are conflicting reports on the effect of moisture content on the rupture force. Eckhoff et al. ${ }^{[37]}$ reported that significant differences in peak force of both soft and hard wheat were caused by differences in moisture content at levels of $9 \%, 11 \%$, and $13 \%$, respectively. The main elements of softness and hardness were related to particle size index ${ }^{[38]}$. These mechanical properties are often relevant to the designs, improvement, and optimization of food processes ${ }^{[32]}$.

3.4.3 Interaction effect of moisture contents and loading speeds

The interaction effect of moisture contents and loading speeds on vertical and lateral rupture forces are presented in Figure 5c. The data indicated that vertical and lateral rupture force varied from 362.78 to $286.71 \mathrm{~N}, 338.21$ to $286.71 \mathrm{~N}, 322.6$ to $268.8 \mathrm{~N}$, 322.96 to $260.00 \mathrm{~N}, 320.4$ to $246.8 \mathrm{~N}$ and 707.56 to $684.60 \mathrm{~N}$, 697.71 to $679.40 \mathrm{~N}, 588.6$ to $575.8 \mathrm{~N}, 673.8$ to $661 \mathrm{~N}, 669.4$ to $560.4 \mathrm{~N}$ with the change of moisture for loading speed of $5,10,15$, 20 and $25 \mathrm{~mm} / \mathrm{min}$, respectively.

Furthermore, the highest vertical and lateral rupture force $(362.78$ and $707.56 \mathrm{~N}$ ) was observed at loading speed of $5 \mathrm{~mm} / \mathrm{min}$ and moisture of $11.2 \%$. Whereas, lowest (246.8 and $560.4 \mathrm{~N}$ ) was found at loading speed of $25 \mathrm{~mm} / \mathrm{min}$ and moisture of $21.3 \%$. The loading speed and moisture content significantly affected the rupture force.

Hence the results illustrated that beyond the linear limit, the rupture force increased at a faster rate than the loading speed. This made it possible to evaluate the linear limit load beyond which the load-ruptures force was no longer linear for each moisture level. 


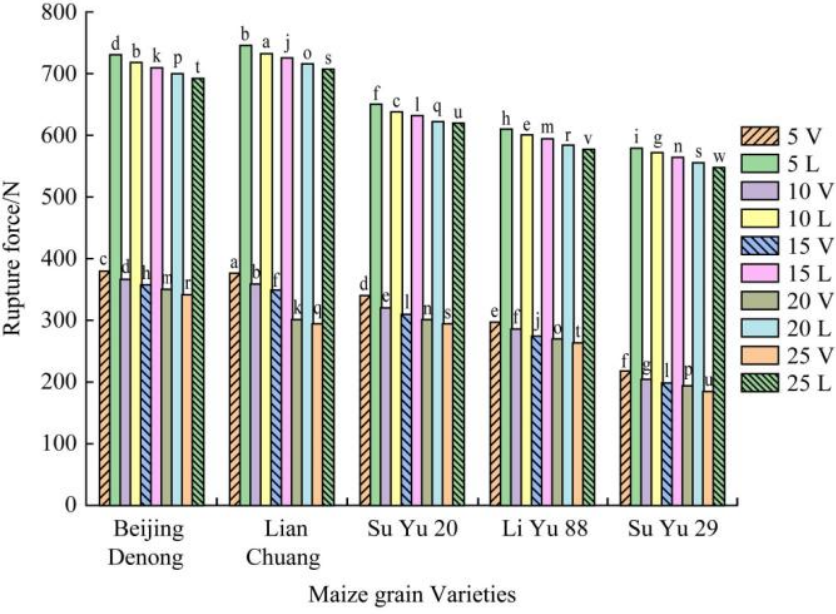

a. Interaction effect of varieties and loading speed

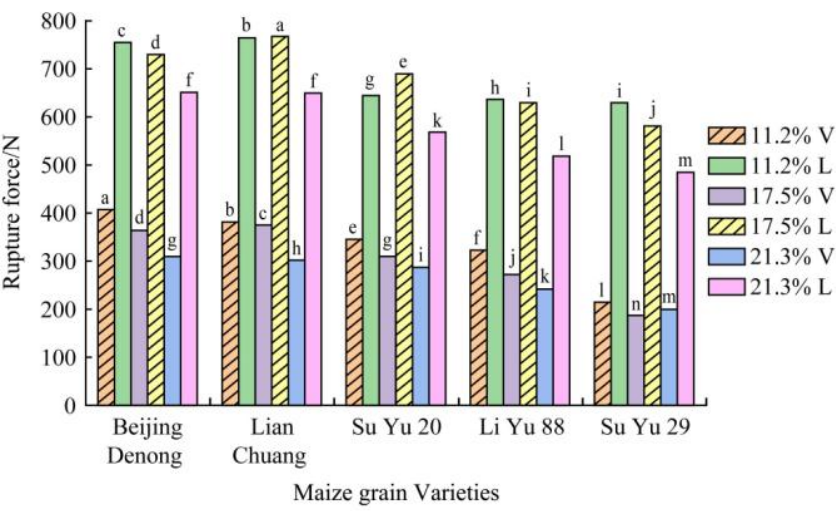

b. Interaction effect of maize grain varieties and moisture contents

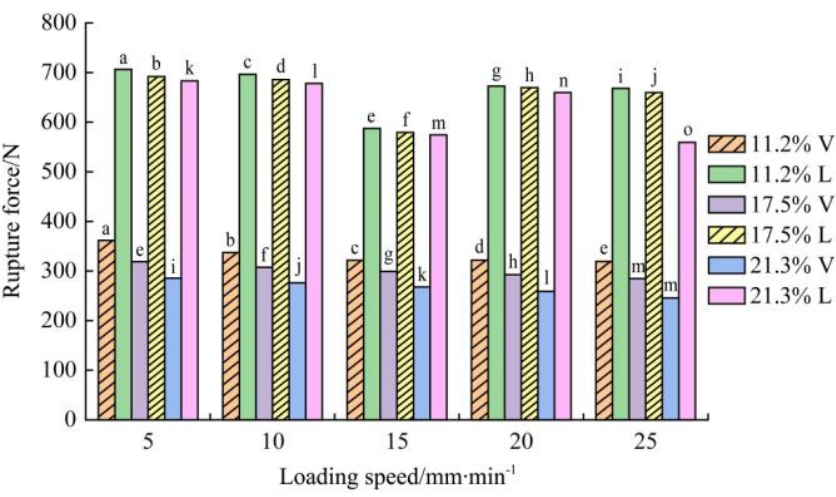

c. Interaction effect of moisture contents and loading speeds

Note: Legend represents vertical/lateral rupture force under a certain loading speed/moisture content, e.g., $5 \mathrm{~V}$ represents vertical rupture force under loading speed of $5 \mathrm{~mm} / \mathrm{min}$.

Figure 5 Interaction effects on vertical and lateral rupture force

\subsection{Mechanical properties at the rupture point}

\subsubsection{Deformation at the rupture point}

The mean values of vertical and lateral deformation of maize grain for three moisture contents and five varieties are presented in Figure 6a. The average values were ranged from 0.65 to $1.88 \mathrm{~mm}$ for vertical deformation and 0.52 to $0.81 \mathrm{~mm}$ for lateral deformation at three moisture contents $(11.2,17.5$, and $21.3 \%)$ for five varieties (Beijing Denong, Lianchuang, Suyu 20, Liyu 88 and Suyu 29), respectively. Furthermore, the highest moisture content provides flexibility and elasticity to grain varieties during deformation at the rupture point. Higher moisture content and lower loading speed resulted in more mechanical damage. Similar trends were reported by Lupu et al. ${ }^{[39]}$

3.5.2 Hardness at the rupture point

The mean values of the vertical and lateral hardness of maize grain for three moisture contents and five varieties are presented in Figure $6 \mathrm{~b}$. The average values were ranged from 711.06 to $381.65 \mathrm{~N} / \mathrm{mm}$ for vertical hardness and 91.10 to $370.99 \mathrm{~N} / \mathrm{mm}$ for lateral hardness at three moisture contents $(11.2 \%, 17.5 \%$, and $21.3 \%$ ) for five varieties (Beijing Denong, Lianchuang, Suyu 20, Liyu 88 and Suyu 29), respectively. The effect of moisture content on hardness was found to be significant $(p<0.05)$. The hardness of maize grain showed significantly $(p<0.05)$ different at three moisture contents. Further results revealed that the highest vertical hardness was obtained for $17.5 \%$. The results are in agreement with those reported by Soomro et al. ${ }^{[40]}$ for rough rice. Water absorption behavior associated with hardness was reported to be dependent on grain geometric size, shapes, and physical structure. According to the report by Armstrong et al. ${ }^{[41]}$, hardness was often used to reflect the ratio of hard (corneous or vitreous) to soft (starchy) endosperm.
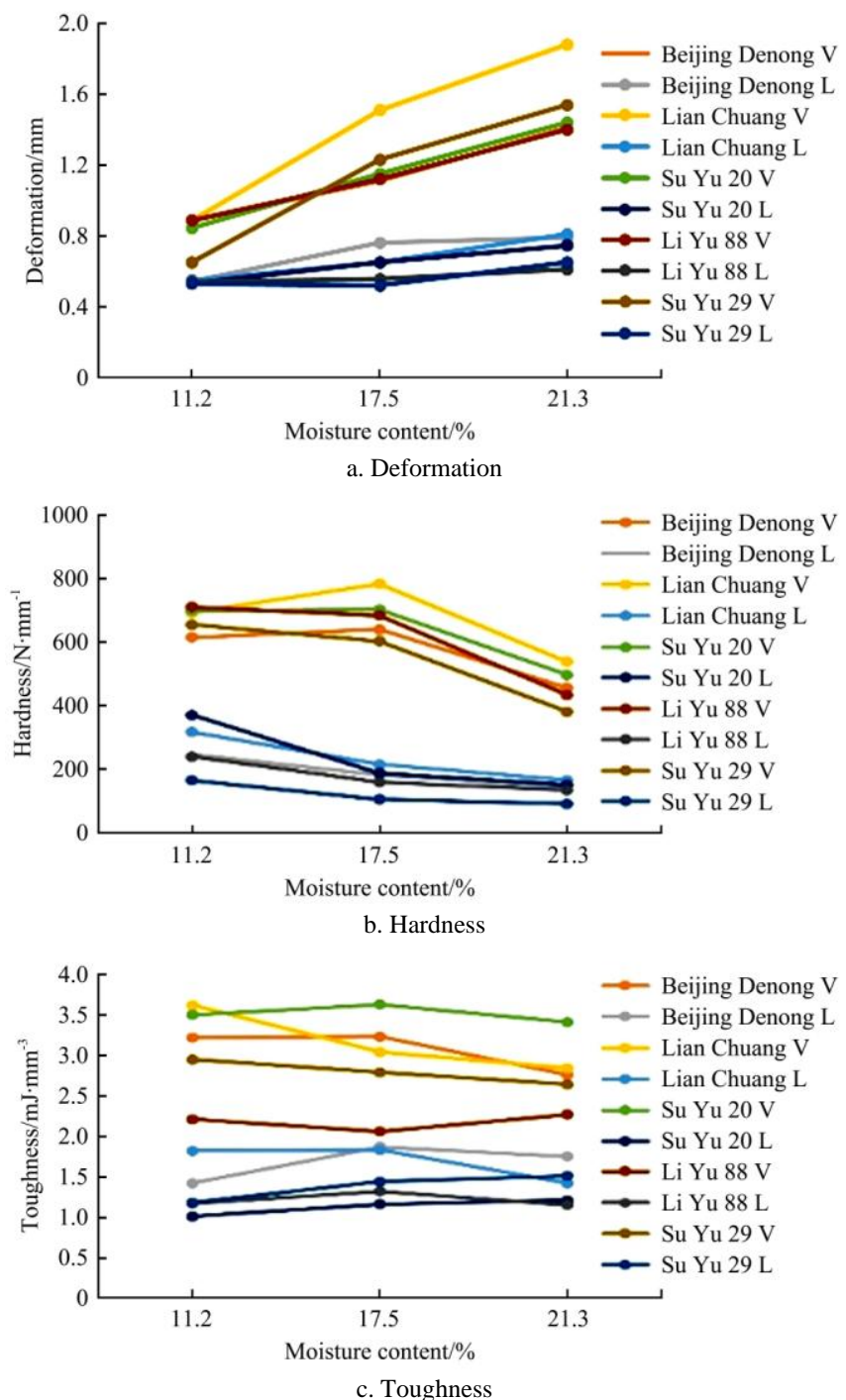

Figure 6 Effects of moisture content on the mechanical properties of maize grain at the rupture point

\subsubsection{Toughness at the rupture point}

The mean values of vertical and lateral toughness of maize grain for three moisture contents and five varieties are presented in Figure 6c. The average values were ranged from 3.63 to $2.95 \mathrm{MJ} / \mathrm{mm}^{3}$ for vertical toughness and 1.87 to $1.15 \mathrm{MJ} / \mathrm{mm}^{3}$ for lateral toughness at three moisture contents $(11.2 \%, 17.5 \%$, and $21.3 \%$ ) and five varieties (Beijing Denong, Lianchuang, Suyu 20, Liyu 88 and Suyu 29), respectively. The results of Beijing 
Denong, Lianchuang, Suyu 20, Liyu 88, and Suyu 29 of maize grain varieties ranged from 3.63 to 2.95 and 1.87 to $1.15 \mathrm{MJ} / \mathrm{mm}^{3}$ for Beijing Denong, Lianchuang, Suyu 20, Liyu 88 and Suyu 29) towards $11.2 \%, 17.5 \%$, and $21.3 \%$. Furthermore, the highest toughness was obtained towards Suyu 20 towards vertical and lateral orientations, whereas the lowest was obtained for Suyu 20.

The vertical toughness of the Suyu 20 was found significantly higher $(p<0.05)$ than that of other varieties at higher moisture content. Furthermore, increasing the volume of maize grains increased the moisture content, while energy absorbed decreased. According to the definition of toughness mentioned above, the reason for this decrease results from the fact that the energy absorbed by the grain decreased and the volume of grain increased as the moisture content of the grains increased. Toughness decreased with increases of moisture content from $7.78 \%$ to $16.72 \%$. The toughness of maize grains at the rupture point was reduced by increasing moisture content from $10 \%$ to $30 \%{ }^{[42]}$.

\section{Conclusions}

The moisture content and loading speed significantly affected the physical and mechanical properties of maize grain. The mean length, width, thickness, geometric mean diameter, equivalent diameter, arithmetic diameter, sphericity, volume, surface area, and aspect ratio of maize grain showed response with the change of moisture contents $(11.2 \%, 17.5 \%$, and $21.3 \%)$. The minimum rupture force, hardness, and toughness were obtained at moisture contents of $21.3 \%$, whereas the maximum corresponded to the moisture of $11.2 \%$. Furthermore, increasing the moisture content from $11.2 \%$ to $21.3 \%$, vertical and lateral rupture forces, hardness, and toughness decreased. The highest lateral and vertical rupture forces were noticed $(p<0.05)$ at loading speed of $5 \mathrm{~mm} / \mathrm{min}$. Moreover, increasing the loading speed from 5 to $25 \mathrm{~mm} / \mathrm{min}$, vertical and lateral rupture forces decreased. It is concluded that the properties of maize grain were related to the design of planters, harvesters, threshers, and processing machines.

\section{Acknowledgements}

This research was financially supported by the National Key Research of Development Program of China (Grant No. 2016YFD0702004), the National Natural Science Foundation of China (Grant No. 51975256), Jiangsu Key Research and Development Program of China (Grant No. BE2016356).

\section{[References]}

[1] Zoerb G C, Hall C W. Some mechanical and rheological properties of grains. Journal of Agricultural Engineering Research, 1960; 5: 83-92.

[2] Saul R A, Steele J L. Why damaged shelled corn costs more to dry. Agricultural Engineering, 1966; 47: 326-329.

[3] Shelef L, Mohsenin N N. Effect of moisture content on mechanical properties of shelled corn. Cereal Chemistry, 1969; 46: 242-253.

[4] Josef E. Principal corn kernel damages (Handout). USDA Agricultural Marketing Services, Kansas City District, 1990.

[5] Gomez F. Influence of mechanical damage on corn seed quality. Master dissertation. Mississippi State: Mississippi State University, 1971; 43p.

[6] Sandhu K S, Singh N, Malhi N S. Some properties of corn grains and their flours I: Physicochemical, functional and chapati-making properties of flours. Food Chemistry, 2007; 101: 938-946.

[7] Puchalski C, Brusewitz G H, Slipek Z. Coefficients of friction for apple on various surfaces as affected by velocity. Agricultural Engineering International: CIGR Journal of scientific research and development, 2003; 5: $1-14$.

[8] Mamman E, Umar B, Aviara N A. Effect of moisture content and loading orientation on the mechanical properties of Balanites Aegyptiaca nuts.
Agricultural Engineering International: CIGR Journal of scientific research and development, 2005; 7: 1-16

[9] Razavi S M, Rafe A, Moghaddam T M, Amini, A M. Physical properties of pistachio nut and its kernel as a function of moisture content and variety. Part II. Gravimetrical properties. Journal of Food Engineering, 2007; 81: 218-225.

[10] Gezer I, Haciseferoğulları H, Demir F. Some physical properties of Hacihaliloğlu apricot pit and its kernel. Journal of Food Engineering, 2003; 56: 49-57.

[11] Fathollahzadeh H, Mobli H, Beheshti B, Jafari A, Borghei A M. Effects of moisture content on some physical properties of apricot kernel $(\mathrm{CV}$. Sonnati Salmas). Agricultural Engineering International: CIGR EJournal, 2008; 10: 1-14.

[12] Khazaei J, Mann D D. Effects of temperature and loading characteristics on mechanical and stress-relaxation properties of sea buckthorn berries. 1 Compression tests. CIGR Journal of scientific research and development, 2004; 3: 1-9.

[13] ElMasry G, Moltó E, Blasco J, ElSayed A. Influence of hot water treatment on some chemical and mechanical properties of potato. Agricultural Engineering International: CIGR EJournal, 2006; 8: 1-10.

[14] Sessiz A, Esgici R, Kizıl S. Moisture-dependent physical properties of caper (Capparis ssp.) fruit. Journal of Food Engineering, 2007; 79: 1426-1431.

[15] Li Y, Chandio F A, Ma Z, Zaman M, Soomro S A. Post harvesting technology: effects of moisture content and loading speed on shearing failure of paddy grains. International Agricultural Engineering Journal, 2018; 27: 342-349

[16] Li Y, Chandio F A, Ma Z, Lakhiar I A, Sahito A R, Ahmad F, et al Mechanical strength of wheat grain varieties influenced by moisture content and loading rate. International Journal of Agricultural and Biological Engineering, 2018; 11: 52-57.

[17] Zoerb G C. Instrumentation and measurement techiniques for determining physical of farm products. Transactions of ASAE, 1967; 10: 100-109.

[18] Singh K K, Goswami T K. Mechanical properties of cumin seed (Cuminum cyminum Linn.) under compressive loading. Journal of Food Engineering, 1998; 36: 311-321.

[19] Wang B, Li D, Wang L, Huang Z, Lu Z, Xiao D C, et al. Effect of moisture content on the physical properties of fibered flaxseed. International Journal of Food Engineering, 2007; 3: 7, 1-11.

[20] Kara M, Turgut N, Erkmen Y, Guler I E. Determination of coefficient of friction of some granules. 17 National Symposium on Mechanization in Agriculture. Tokat-Turkey, 1997; 609-614. (in Turkish)

[21] Mohsenin N N. Physical properties of plant and animal materials Gordon and Breach. New York: Science Publishers, 1970.

[22] Jain R K, Bal S. Properties of pearl millet. Journal of Agricultural Engineering Research, 1997; 66: 85-91.

[23] Omobuwajo T O, Akande E A, Sanni L A. Selected physical, mechanical and aerodynamic properties of African breadfruit (Treculia africana) seeds. Journal of Food Engineering, 1999; 40: 241-244.

[24] Tavakoli H, Rajabipour A, Mohtasebi S S. Moisture-dependent some engineering properties of soybean grains. Agricultural Engineering International: CIGR EJournal, 2009; 11: 1-14.

[25] Gupta R K, Das S K. Fracture resistance of sunflower seed and kernel to compressive loading. Journal of Food Engineering, 2000; 46: 1-8.

[26] Sirisomboon P, Kitchaiya P, Pholpho T, Mahuttanyavanitch W. Physical and mechanical properties of Jatropha curcas L. fruits, nuts and kernels. Biosystems Engineering, 2007; 97: 201-207.

[27] Milani E, Seyed M, Razavi A, Koocheki V, Nikzadeh N, Vahedi M, et al. Moisture dependent physical properties of cucurbit seeds. International agrophysics, 2007; 21: 157-168.

[28] Karababa E, Coşkuner Y. Moisture dependent physical properties of dry sweet corn kernels. International Journal of Food Properties, 2007; 10: 549-560.

[29] Isik E, Izli N. Moisture dependent physical and mechanical properties of dent corn (Zea mays var. indentata Sturt.) seeds (Ada-523). Am J Food Technol, 2007; 2: 342-353.

[30] Deshpande S O, Bal S, Ojha T P. Physical properties of soybean. J of Agri Engg Res, 1993; 56: 89-98.

[31] Altuntas E, Yildiz M. Effect of moisture content on some physical and mechanical properties of faba bean (Vicia faba L.) grains. Journal of Food Engineering, 2007; 78: 174-183.

[32] Tarighi J, Mahmoudi A, Alavi N. Some mechanical and physical 
properties of corn seed (Var. DCC 370). African Journal of Agricultural Research, 2011; 6: 3691-3699.

[33] Alibas I, Koksal N. The effect of moisture content on physical, mechanical and rheological properties of soybean (Glycine max cv. ATAEM-II) seed. Legume Research-An International Journal, 2015; 38: 324-333.

[34] Wang Y, Li L, Gao S, Guo Y N, Zhang G Q, Ming B, et al. Evaluation of grain breakage sensitivity of maize varieties mechanically-harvested by combine harvester. International Journal of Agricultural and Biological Engineering, 2020; 13: 8-16.

[35] Barnwal P, Kadam D M, Singh K K. Influence of moisture content on physical properties of maize. International Agrophysics, 2012; 26: 331-334.

[36] Babic L J, Radojein M, Pavkov I, Babic M, Jan T, Zoranovic M, et al. Physical properties and compression loading behaviour of corn seed. International Agrophysics, 2013; 27: 119-126.

[37] Eckhoff S R, Supak W A, Davis A B. A rapid single-kernel wheat hardness tester. Cereal Chem, 1988; 65: 503-508.
[38] Jolly C J, Rahman S, Kortt A A, Higgins T J. Characterisation of grain-softness protein, a marker of endosperm texture in wheat. In: Proceedings of the 40th Australian Cereal Chemistry Conference, Victoria-Australia, 1990; 92.

[39] Lupu M I, Pădureanu V, Canja C M, Mazarel A. The effect of moisture content on grinding process of wheat and maize single kernel. Material Science and Engineering, 2016; 145: 022024. doi: 10.1088/1757-899X/ $145 / \mathrm{s} / 022024$.

[40] Soomro S A, Chen K, Soomro S A. Mathematical modelling and optimisation of low-temperature drying on quality aspects of rough rice. Journal of Food Quality, 2020; 20(3): 1-10.

[41] Armstrong P R, Lingenfelser J E, McKinney L. The effect of moisture content on determining corn hardness from grinding time, grinding energy, and near-infrared spectroscopy. Applied Engineering in Agriculture, 2007; 23: 793-799.

[42] Landry J, Delhaye S, Damerval C. Protein distribution pattern in floury and vitreous endosperm of maize grain. Cereal chemistry, 2004; 81: $153-158$. 